\title{
The technique of conservation: on realms of theory and cultures of practice
}

\section{Dr Hanna Hölling}

To cite this article: Dr Hanna Hölling (2017): The technique of conservation: on realms of theory and cultures of practice, Journal of the Institute of Conservation

To link to this article: http://dx.doi.org/10.1080/19455224.2017.1322114

Accepted author version posted online: 08

May 2017.

Submit your article to this journal

Q View related articles $₫$

View Crossmark data \lceil 
Publisher: Taylor \& Francis \& Icon, The Institute of Conservation

Journal: Journal of the Institute of Conservation

DOI: $10.1080 / 19455224.2017 .1322114$

\section{The technique of conservation: on realms of theory and cultures of practice}

\section{What is conservation?}

Simplistic as it may seem, there are many possible answers to the question: What is conservation? Today, conservation no longer aims simply to prolong its objects' material lives into the future. It is now seen as an engagement with materiality, rather than material [1] - that is, its now considered as contending with many specific factors that determine how an objects'identity and meaning are entangled with the aspects of time and space, the environment, values, politics, economy, conventions, and culture. Additionally, beyond its concern with objects, conservation has now also begun to engage with subjects, and the accompanying notions of the transmission of tradition, memory, skill, technique and including the conveyance of knowledge, whether tacit or explicit, embodied or non-embodied. As an entanglement of theory and practice, and seen from a diachronic perspective, conservation is an altogether distinct theoretical-practical construct - a complex sum of approaches and processes that refuses to fall into pre-established categories.

[Insert Fig.1 - Jeff Wall image]

But to ask what conservation is also means scrutinizing the context in which, and the reason why, we need to pose the question. Today, it no longer seems feasible to perform, and to discuss, conservation without including a reflection on its historiography and considering it within a broader context - that of the history of humanities in particular and culture in general. Outside the field, apppreciating the richness of conservation's knowledge-base helps to bypass its somewhat limiting bondage with object-oriented materialism and authenticism that for decades exposed its material interests and, at times, annihilated the need for context. At this point in the new millennium its time for conservation to be contextualized within the broader cultures that produce it and within the human sciences within which it operates [2].

Therefore, I will attempt to sketch a picture of conservation that is distinct from the conventional yiey from the confined microcosms of its specializations. Conservation always exists somewhere between a set of dichotomies: of hands and minds, practice and theory, hard sciences and humanism, the tangible and the intangible, and the traditional and the new. By putting today's conservation into an historical perspective, and setting it against the background of its development in the nineteenth and twentieth centuries, this essay is an attempt at a new historiography of conservation. I will trace, among other things, how the attention paid to materials effectuated from the persistence of science, which, since the mid-nineteenth century, has actively contributed to its shifting identity from the artisanal craft and artistic activity to that of an (apparently) exact science. Such a shift should not be mistaken as an ultimate emancipation. At present, while acknowledging the importance of its romance with science, conservation seems to simultaneously reach beyond it to become considered as a critical act of valourization and interpretation. As such, the cultures it engages, and those it produces, still need to be fully understood. 
Drawing on these perceptions, in what follows the complexities of conservation are not seen as a hindrance. After all, with its material consciousness [3] conservation is perhaps one of the very few areas with the ability to engage with nearly every sort of producer and material in nearly every extant technique enacted in diverse social-technical milieus. Therefore, the titular realms of theory and cultures of practice - the combination of textual, material, and social, but also epistemic practice (that is, the conjunction of practical and propositional knowledge that conservation utilizes and generates)—epitomizes intellectual inquiry and technical knowhow.

Just like the heterogeneity of conservation as argued here, the perspective from which this paper has been written is multifocal. The following insights are inspired by the author's longterm commitment to conservation practice, stewardship of collections, participation in the cultures of making, and passion for academic discourse.

\section{Conservation and knowledge}

Conservation is a research and knowledge-generating activity. This dimension has been implicit in conservation for decades but only recently has gained attention in the course of interdisciplinary projects that recognise the importance of such knowledge-generation. [4] Certainly, a profound engagement with conservation practices and theories offers a glimpse into the construction of knowledge and into the attribution and creation of meaning. By dissecting the tools, technologies, modes of decision-making and ethical guidelines persuasive in a given historical period and in a certain geographical zone, one can access the historical conditions that triggered the modes of interpretation of artefacts and, subsequently, the creation of meaning. Yet there is more to this knowledge, especially when related to recent phenomena in cultural production - in the case of iterant artworks that demand continuous reinstallation and reenactment (such as multimedia, installation, performance), conservation produces knowledge by actively and creatively contributing to the these artworks' subsequent materializations. Part of this knowledge is formulated into conservation narratives; the other part, of technique and method, the non-propositional knowledge, is hardly graspable, often remaining within the domain of the implicit and non-verbal. Therefore, it can be said that conservation partakes in the construction of both the historicity, that is, historical actuality and the materiality of its objects.

\section{Terms, taxonomies, contingencies}

For the sake of terminological clarity, 'conservation' is used throughout the text to indicate a more general meaning of conservation-restoration-preservation. As part of technical science, conservation comprises, among other things, all actions related to the manipulation of objectstheir examination, documentation, and maintenance that, to varying degrees, is oriented towards securing these yorks' existence and survival. 'Conservation' also incorporates its theoretical foundation, the construction of its knowledge, but also an understanding of the objects and their makers, and tacit, unarticulated knowledge of specific techniques, approaches, along with its archival systems. Unless used specifically in an historical or technical context, 'conservation' generally stands in for either 'restoration,' or 'preservation,' as contingent on the context in which they are used. [5]

To conserve means to attempt to limit or impose some kind of order onto the contingent world; this poses an interesting paradox, because the notion of conservation itself is anything but fixed or determined. Perhaps, then, we could speak of the contingency of conservation as an alternative that gestures towards a critical reflection on what would be an otherwise normative and linear historiography of the field.

Consequently, conservation should be seen as a complex techno-cultural practice with a strong, retroactive impact on its objects and subjects: the technological aspect of conservation refers to the application of science and technical means in everyday participatory practice and its 
cultural aspect includes those epistemic practices that entail the construction of its knowledgebase, and the enactment of values, judgments, beliefs, and emotions linked with meaning-making activities embedded in distinct cultural milieus. Less a practically oriented activity toward the purposes of efficiency, the techno-cultural practice of conservation that I have in mind is the sum of technical potentialities and cultural attitudes.

\section{Between tradition and reinvention: bunglers and scientists}

The conservation of fine art has a long history of beginnings marked by various modes of practice and principles, in the course of which theories have emerged only in the very recent past. It is often assumed-explicitly or implicitly — that the development of conservation is progressive, that is, that later achievements in conservation are an improvement on former ones. For many, this moment allowed for the development of conservation from restoration and its separation from working-class artisanship. [6] Contrary to any progressive or linear model, conservation has continued to reinvent itself throughout history and arguably in multiplicitous and nonlinear ways. Artisanship has never disappeared, and conservations 'scientism' goes hand in hand with its development across the humanities. As a result, we might speak of different cultures of conservation — artisanal, artistic, scientific, and 'humanistic', that is, value based and phenomenological - which have existed parallel to each other throughout history and which have generated, and were instigated by, distinct kinds of knowledge.

Where Pliny the Elder provides the earliest written evidence for the conservation of antiquities in the first century $\mathrm{AD}$, although without detailing any actual techniques, [7] it is in the Renaissance that the foundations for modern conservation were first laid. From the accounts of Cellini, who provided written descriptions of their methods and thoughts, we learn about the attitudes and approaches of Renaissance restorers. In the skilled hands of artists-restorers and artisans, the rapid development of restoration was mainly dictated by the tastes of the time, and became popularized with the rise of antiquarianism. Albeit demanding both skills and understanding of materials, restoration seemed at times to have been held in low regard, as confirmed by Cellini who wrote it is by no means proper for me to patch up old statues, as that is generally done by a sort of bunglers in the business, who acquit themselves very indifferently.' [8] From the perspective of an artist, doing the job of mending other masters' crumbling sculptures was neither considered artistic nor even as honourable work.

The discoveries of Pompeii and Herculaneum and their subsequent excavations impelled the development of preservation techniques. It is not without reason that the roots of scientific conservation are ascribed to the rise of archaeological conservation. Scientists at the end of the eighteenth century and beginning of the nineteenth century began involving themselves in the treatment of antiquities. Here, the emphasis was on the understanding of materials themselves rather than on the actual treatment of what were predominantly archaeological objects. The development of scientific laboratories at museums in general, and especially the work of Friedrich Rathgen in Berlin, among others, laid the groundwork for the rise of a scientific-based conservation concerned with the examination of materials and the processes of their deterioration. [9] It is neither possible to summarize here the impact of the first conservation publications in the field, nor to provide an account of the development of material studies in Europe and in the U.S. resulting from these approaches. However what is important to note is that such a scientific approach to the conservation of archaeological artefacts had an immense impact on the development of the positivistic, analytic branch of conservation, a form later linked through common disciplinary origins with the emerging specialism of the so-called 'technical art history'.[10]

The introduction and acceptance of scientific analysis as a key in the understanding of artworks resulted in the establishment of conservation as being based on the conviction that 
truths about objects can be revealed through science. [11] According to Steven Dykstra, 'there was a belief that the authority of science and scientific technologies would complement the art of restoration and lend it the type of credibility that was carved out in the natural sciences. There was a confidence that a measure of scientific objectivity would dispel any perceptions of art restoration as an entirely interpretative and unrestrained process.' [12] Here, conservation strives to enforce the 'truth' conveyed in the object, something usually related to its physical, historical, and aesthetical integrity. [13] The ability to gain objective knowledge through scientific analysis led to notions of authenticity prefigured around 'original object' and 'original condition,' [14] and a specific understanding of artists' intentions through the discernment of physical matter. Traditional conservation theory added to these dicta both 'minimal intervention,' which was regarded as a fundamental principle in the 1970s, and the closely associated idea of 'reversibility', and both have strongly guided conservation practices ever since as they derive from a positivist belief in objectivity.[15] Broadly speaking, early conservation theories were established in the context of the restoration of artworks that are conceived as unique objects often in a singular medium, the cult of artist-as-genius_-beginning with Vasari [16] and culminating in Romanticism - and irrevocably linked with notions of intentionality.

\section{Traditional and new theories: from object-centrism to relativism}

In general, it can be said that that science-based conservation is oriented towards ocular and structural aspects; it is object-based and rests on a scientific positivism around objectivity with an epistemic of objects as conveyors-of-truth. Humanistic conservation is bound with culture and people, and oriented towards the values established by them. This conservation embraces an inclusive, relativistic, pluralistic, and all-encompassing view of the network of people and things [17] in which people and objects assume equivalently significant positions [18] Such an approach acknowledges artworks as cultural products, dynamic entities, the materiality of which can only be identified in such an entangled network of relations and under the consideration of social and temporal aspects. Rather than seeking evidence of the artwork's past exclusively under a microscope, the conservation addressed here allies with the social sciences, philosophy (including aesthetics), and archaeology. In this kind of conservation, which begins to distance itself from authenticity, artworks and artefacts are seen as processes evolving and changing in time, nonreducible to a particular condition at one particular time as discernable by measurement and analysis. Although the role of ethnographic conservation in reformatting the scope of the field by looking at living heritage (e.g. First Nations) cannot be underappreciated,[19] it is the developments in recent art and media that have imposed a radical rethinking of conservation paradigms and principles. I will return to them after providing a brief overview of conservation's early theories.

According to Paul Philippot, the development of conservation as an historical discipline based on method might be located in the nineteenth century when Canova refused to add missing elements to the sculptural ensemble of Parthenon, while, on the other hand, Thorvaldsen consented to restoring the Aegina Marbles in the neoclassical style.[20] The concepts expressed in nineteenth-century restoration rhetoric contributed to the development of conservation: the crystallization of fine-art conservation theories were preceded by theories of architectural restoration laid out by Eugène-Emmanuel Viollet-le-Duc in France (restoration is 'modern' and must follow the unity of style) and opposed in Britain by John Ruskin (antiquarian attitude) and William Morris ('honest repair') but also elsewhere by Alois Riegl (theory of values) and Camillo Boito ('theory of philological conservation').[21] Although the past century has brought various theoretical voices into the discussion the historical and aesthetic dimension of restoration found its major expression in the theory formulated and published by Italian art critic and historian 
Cesare Brandi in 1963.[22]

In his Theory of Restoration, Brandi sees restoration as a 'methodological moment,' that is, a means of recognizing a work of art in its aesthetic and physical being. [23] He further assigns a high value to the historical and material authenticity of the artwork. [24] Using the principles of Gestalt psychology, Brandi sees an artwork as a set of relationships among its constituent parts, rather than their sheer sum, and bases his theory on the presumption of the univocality of artistic intent. Brandian axioms are succinct: he postulates, among other things, the minimization of the randomness of taste and subjectivity in the process of making a decision concerning conservation, the unacceptability of creative conservation, where the conservator should never imitate or substitute the artist as conservation deals with the object in the present, not at the time of its creation. [25] He further advocates for the complete reversibility of restoration work and respect for the history of an artwork. The founding principle of his theory was the unity of an artwork, that is, its nondivisibility into constitutive elements and further conceived in the relation between the work's 'aspect' (aspetto, or image) which needs to be preserved unaltered and its structure (struttura, structure) which can be subject to restoration. [26]

Published in 1963, Brandi's work was only translated into English much later with fragments revealed to an international readership by the end of the twentieth century. The reason it is so important to consider Brandian thought in the light of the dialectic of science and the humanities in conservation is because, in its anti-positivist leanings, Brandian thought insisted on artistic, historical, and aesthetic criteria as being pre-requisite in conservation. Brandi opposed the judgment of paintings solely by their chemical, physical, and technical criteria—a position which contributed to the so-called Ruhemann-Gombrich debate which centered around the controversies that arose due to the cleaning of paintings in London's National Portrait Gallery and which revealed how the values of conservation can conflict with the facts derived from scientific analysis. [27] The Austrian-British art historian Ernst Gombrich, who, like Brandi, was a proponent of the understanding of an artwork in a broader set of relationships including its historic and aesthetic context, later commented: 'People are blinded by the analysis of the medium that they forget the other half.' [28]

To some degree, this statement still holds true for the status quo of conservation in the twenty first century. Most importantly, it demonstrates that conservation is conditioned upon an underlying uncertainty about where and how the object is. However, conservation's search for its 'object' is surrounded by an ambiguity resulting from the impossibility of balancing the general and the particular, and the ability to distinguish, as Thordis Arrhenius puts it, 'between true and false, beginning and end, original and appliqué.' [29]

Lastly, traditional conservation is too often and too simply juxtaposed with new approaches. For what is considered new conservation frequently refers to the practice oriented towards recent media, which is not necessarily equivalent with new theoretical thinking. [30] Similarly, novel conservation thinking might just as well apply to traditional art and artifacts. In practice, attitudes and concepts often intersect and the most innovative voices never remain entirely free from the strictures of the past. Clearly, conservation's theoretical underpinnings are neither entirely progressive, nor exclusive.

\section{Old and new: singularity and plurality}

It is not to say, of course, that there is no movement on the horizon of innovation. Recent conservation theory sources analytic and continental philosophies, social studies, performance studies, and archaeology. In a similar way to ethnographic conservation that references other knowledge domains to come to terms with the dynamic character of heritage, the conservation of contemporary art strives to grasp its objects' nature and behaviour through implementing a heurism of value-based, phenomenological and theoretical approaches to its object. The division 
between the intangible and the tangible - which Frank Hassard took on in his brilliantly formulated thesis concerning the ideological division in conservation where he relates the former to the living mediation of the latter[31] - seems to be reunited again in discussions around media art preservation.

Undoubtedly, the often transitory, processual, and conceptual/intangible aspects of art created since the 1960s has forced conservation out of its object-oriented comfort zone.

Traditional painting or sculpture can be understood in terms of their material constitution, history of creation, authorship, and display deduced either from the object or from the recorded evidence. In turn, defining the specificity of the physical medium of a multimedia artwork including, for example, moving images, organic materials, and sculpturally significant display and playback apparatus, may not be sufficient in order to understand what and how the artwork is both with reference to its present and to its (imagined) future. Recent artworks often fail to be classified according to the paradigms of material authenticity as supported by identification of their physical and chemical make-up. What could be learned about a multimedia artwork if it were decomposed into its material constituents? What can the type of TV set used, the thickness of the phosphor coating on the inner wall of its screen or the acceleration of electrons activated in its cathode ray tube tell us about it? What could be learned about a performance work if we only looked at the physical constituency of a human body? Media installations, performances, events, and processes are complex entities in which all components exist in a set of fragile relationships, including the space they inhabit, the viewer and the performance of these elements over time. They are inextricably linked with the concepts of duration, change, and experienceaspects that demand a new set of conceptual tools in conservation. Rather than only the artworks' vehicular media - the physical carriers of artworlks - conservation has to grapple with artistic media that mediate between what the artist does and what the work says. The dialectic of concept and material is complicated by intricate materialities - plastic, electronics, code and organic-based media all with their specific processes of decay - as well as extended collaborations and distributed authorship all of which impact on the current paradigms of conservation. The aesthetics of change, iteration, cyclical materialization, reconfiguration, and fragmentation, but also the quest for the decentring of authorial agency, so characteristic of a post-Cagean era, demand an entirely different intellectual mindset. Can a work of art be remembered, collectively or individually, rather than conserved, and if so, how? Can documentation stand in for the work in its absence? How can a fragment become representative of the artwork? Can a conservator assume an active and creative agency in the artwork? These are only a few among the many questions posed in current conservation thought. It might be said that the primacy of hands and the implementation of the technical knowhow has been left behind by the conceptual aspects involved in the perpetuation of this kind of cultural expression.

2 Change has also arrived at the forefront of the discourse of material authenticity omnipresent in the polemics of traditional conservation. 'Authentic' always requires a referent, an indexical dimension to relate to, as not all authentic objects are authentic in every respect. In conservation, authenticity usually relates to an act of selection of a moment in the genealogy of artwork to authenticate its relation to time and to reconfirm its value both as a historic artefact and as a commodity. Instead, taking into consideration the artworks' entire trajectories, newer thinking in conservation acknowledges artworks as palimpsests that accumulate changes, modifications and interpretations.[32] Artworks are interventions in time, they fold time and move through time -a seemingly ungraspable dimension if we leave the realm of measurable clock time. Artworks, just as their world, are permanently impermanent; they are characterized by relative duration, rather than by snapshots of a reality punctuated by the illusion of material authenticity. It seems that the concept of authenticity as it is used in conservation theory might itself become obsolete in the face of recent artistic practices and its accompanying museological 
contexts. Recent examples of augmented reality - including the project devoted to Mark Rothko's Harvard Murals, simulated visual reconstructions such as The Temple of Dendur at the

Metropolitan Museum in New York and the extension of digital print technologies as in the now notorious case of the guerrilla scanning of the figure of Nefertiti in Neues Museum in Berlin - all gnaw at this concept.[33]

My own work in the field of theorization of recent art explores the reciprocal relation between artworks and archive, in which the archive, as a conceptual and physical domain allows for the artwork's actualization dependent on cultural permissions. Rethinking time and its conceptualisation that implicitly underpins conservation appears necessary in order to overcome familiar patterns that redirect us towards the notions of the 'original' or 'authentic' condition. Artworks, as I suggested above, can be conceived as short events or a long process in which conservation interferes. Here, the idea of duration in which the present is the actualization of many different pasts offers an alternative view to the traditional conception of tempotality. Recursions, traces and fragments of works generated in course of a performance that is short durational, that disappears, play an important role in the understanding not only the artwork, but also the work done by the artwork and do something to illuminate the logic behind the collections that hold on to them and the cultures that preserve them.

The conservation of recent art is neither oriented toward, nor learns from, traditional conservation - and this is where the progression of linear historiographies does not apply. While at the first sight this seems an impossible statement, it is predicated on the new character of works and the openness toward the intangible qualities of cultural production (which reminds us of Hassard's division). There is also another consequence to the complex relation between the old and the new: recent theoretical approaches do not just exist as independent constructs, but rather they forever alter our view on the practices and theories of traditional conservation, including its static conception of the object and its relating material authenticity. So perhaps the question that should be posed is not the one of the loss of skill and function of traditional conservation, but whether the continuously evolving concept of conservation still holds what it promises, or, in other words, whether we can continue discussing the paradigms of traditional conservation if there is in fact little, and sometimes nothing, to be physically kept.

\section{By way of conclusion: towards a cultural technique of conservation}

As a complex sum of approaches, attitudes, and cultures, conservation rejects any uniformity. Rather, it constantly seeks to define itself at the crossroads of theory and practice, at the point where custody, stewardship, presentation, and creativity meet. This is why the question of 'what conservation is' seems only at first sight simplistic. In the bigger picture, in balancing between the sciences and the humanities, and artisanal and artistic approaches, conservation both generates and sources distinct types of knowledge to form its identity as a discipline. This is why the question of what conservation is has the character of a second-order question: it interrogates the position from which, and the reason why, it is being posed.

Of course, to say that conservation has a technique would seemingly once more relegate it into an activity devoted to finding technical solutions. Technê was Aristotle's second category of knowledge: skill, craft-competence, and technical knowledge - the knowledge how as opposed to the knowledge of as laid out in the Nicomachean Ethics. While the Greek word technê often refers to manufacturing as well as to the arts, earlier writers, especially Plato, used these both denominations of knowledge almost interchangeably. In his 1977 essay 'The Questions Concerning Technology,' German philosopher Martin Heidegger explains technê as a kind of knowing, an expertise that exceeds a set of practical skills. [34] Directly linked with episteme and its modern form, epistemology that investigates how we know things, technê is elevated to the revealing of making, manipulation, and means, and thus becomes a know-how and an expertise, 
rather than sheer instrumentality concerned with getting things done. For Heidegger 'technology is a mode of revealing,' it 'comes to presence in the realm where revealing and unconcealment take place, where ... truth happens.' [35]

Such revelation is inherent to what has been referred to in this article as the technique of conservation. And arguably it may occur when revisiting conservation's historiography and cultural, rather than material, techniques - a process of revision which has just begun but which is necessary in order to carefully lay out newer philosophies of conservation and to consolidate their presence alongside that of science.

\title{
Acknowledgements
}

Although two decades of work in and with conservation spawned this paper, I was able to conduct a considerable part of research on this topic during my visiting scholarship at the Max Planck Institute for the History of Science in Berlin (2015) - I am grateful to Sven Dupré and my peers for fruitful discussion. I have also benefited from the inspiring intellectual environment of the Bard Graduate Center in New York and the Cultures of Conservation curricular initiative (201315). Last but not least, I was able to revise the final version of this paper during my research residency at the Getty (2017) and I am enormously grateful for the support provided by the colleagues at the Getty Conservation Institute and the Getty Research Institute in Los Angeles.

\begin{abstract}
What is conservation? Simplistic as it may seem, this question has many possible answers. Today, conservation no longer aims simply to prolong its objects' material lives into the future. It is seen as an engagement with materiality, rather than material - that is, with the many specific factors determining how objects' identity and meaning are entangled with the aspects of time, the environment, ruling values, politics, economy, conventions, and culture. Additionally, beyond the concerns with objects, conservation now also engages with subjects, and the accompanying notions of the transmission of skill, tradition, memory and tacit knowledge. By glimpsing into the theories past and present, this paper argues that conservation is a complex techno-cultural practice with a strong, retroactive impact on its objects and subjects. Conservation offers an invaluably rich context to study a man-made world. Simultaneously, it allows us to pursue fundamental epistemic questions related to what, when and how artworks exist in the world and how our engagement with them is contingent upon the prevailing cultural-historical conditions.
\end{abstract}

\section{Biography}

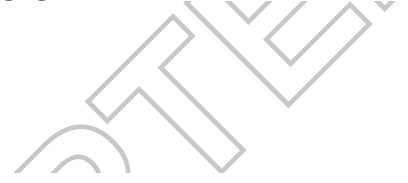

Hanna Hölling is Lecturer in the History of Art and Material Studies at the Department of History of Art, University College London. She works on the intersections of art history and theory, material culture studies and conservation. Her research, writing and teaching focus on the art and cultural developments since the 1960s and 70s and on aspects of time, change, materiality and archive in relation to how we conceive of artworks in terms of objects that endure. Among her books are Revisions-Zen for Film (Bard Graduate Center, 2015) and Paik's Virtual Archive: On Time, Change and Materiality in Media Art (University of California Press, 2017). She was awarded the Andrew W. Mellon Professorship, Cultures of Conservation, at the Bard Graduate Center in New York (2013-2015) and, most recently, the Getty Foundation residential grant for the project Object in Flux (2016-2017, GCI).

Contact address

Dr Hanna Hölling

Lecturer in the History of Art and Material Studies

Department of History of Art

University College London

Gower Street 
London

WC1E 6BT

Email: h.holling@ucl.ac.uk 


\section{$\underline{\text { Footnotes }}$}

This article originated in part as a lecture given at the Max Planck for the History of Science in Berlin in November 2015 (Max Planck Colloquium Series: Art and Knowledge in Pre-Modern Europe).

1. Although the words 'material' and 'materiality' carry ambivalent meanings in English, I understand materiality here as a social and temporal construct framing the existence of artworks and artifacts across different temporal and spatial contexts. In the context of conservation, we speak of the non-material aspects of materiality as including the artwork's concept, temporality, and spatiality. For the physical matter connoted with materiality that assumes potential from its association with non-physical matter, see JeeHee Hong, 'Material/materiality,' The Chicago School of Media Theory (Winter 2003), https://lucian.uchicago.edu/blogs/mediatheory/keywords/materialmateriality/ (accessed 22 May 2016).

2. See, for example, Hanna Hölling, 'The Explicit Material: On the Intersections of Conservation, Art History and Human Sciences,' Simulacrum, Stichting Simulacrum, Kunsthistorisch Instituut, University of Amsterdam, 23/1 (2014): 21-27 and Hanna Hölling, 'Cultures of Conservation-A Study into Objects, Subjects, and Knowledge of Conservation,' unpublished project proposal, 2016 (author's archive).

3. Sennett uses the term of 'material consciousness' outside the context of conservation. He suggests we cultivate a material consciousness by encouraging us to think with and through the tools we use. Although this term has received considerable attention in the field of material studies, my allusion relates merely to the way in which conservation explicates the material by its techniques of a direct engagement with, and the practical uses of, cultural objects.

4. I have in mind, among others, the projects led by Sven Dupré., Artechne: Tecbniques in Arts 1500-1950 at Utrecht University https://artechne.wp.hum.uu.nl/ and the earlier Art and Knowledge at the Max Planck Institute for the History of Science in Berlin https://www.mpiwgberlin.mpg.de/en/research/projects/MRGdupre (both accessed 15 April 2017).

5. There has been much discussion about conservation taxonomies. ICOM-CC, for instance, proposes to split conservation into 'preventive conservation,' 'remedial conservation,' and 'restoration.' ICOM-CC, 'Terminology to Characterize the Conservation of Tangible Cultural Heritage,' no date, http://www.icom-cc.org/242/about-icom-cc/what-isconservation (accessed 20 April 2016). Already in 1870, Manfred Holyoake, in The Conservation of Pictures, described conservation as 'the wider art of preserving as well as restoring the works', see Jonathan Ashley-Smith, 'The Basis of Conservation Ethics,' in Conservation, Principles, Dilemmas and Uncomfortable Truths, eds. Alison Richmond and Alison Bracker (Oxford: Elsivier, 2009), 18. It is a widely held riew, restoration and conservation represent divergent modes of practice.

6 Cf. Paul Philippot, 'Restoration From the Perspective of the Humanities,' in Historical and Philosophical Issues in the Conservation of Cultural Heritage, ed. Nicholas Stanley Price et al. (Los Angeles: J. Paul Getty Trust, 1996), 217.

7. Cf. Catherine Sease, 'A Short History of Archaeological Conservation,' Studies in Conservation, 41, (1996) sup. 1, 157-161.

8. Benvenuto Cellini, Memoires of Benvenuto Cellini, A Florentine Artist; Written by Himself, trans. Thomas Roscoe (London: Henry G. Bohn, 1847), 405.

9. In 1888 Rathgen was appointed head of the chemistry laboratory at the Königliche Museen in Berlin. He was author of Die Konservierung von Altertumsfunden published in 1898. In Britain, a conservation lab devoted to the analysis of materials and archaeological artefacts was founded in 
1920 at the British Museum by Alexander Scott and later with Harold J. Plenderleith. It was only in the 1930s, the focus slowly shifted to fine arts, marked by the publication of Manual of the Conservation and Restoration of Paintings by Helmut Ruhemann et al. (London: Archetype, [1939] 1997). In America Edward Forbes established a research department at the Fogg Art Museum in Cambridge, Massachusetts, run by George Stout, John Gettens and others. In 1932 they established the journal Technical Studies in the Field of Fines Arts, which became a forum for publication of all matters related to conservation. For an account of the evolution of conservation technical studies, see Maryan W. Ainsworth, 'From Connoisseurship to Technical History: The Evolution of the Interdisciplinary Study of Art,' Getty Newsletter 20.1 (2005): 4-10, and for a discussion of the technical examination of artworks as it developed in the United States, see Francesca Bewer, A Laboratory for Art: Harvard's Fogg Museum and the Emergence of Conservation in America, 1900-1950 (Cambridge, MA.: Harvard University Art Museums, 2010).

10. Technical art history was coined by David Bomford in the late 1990s to describe the study pertaining to the materials, methods of art, and intentions of the maker. According to Erma Hermens, this study is concerned with researching the material history of an artefact, which 'goes hand in hand with an increasingly scientific approach in conservation research and methodology, rapidly developing scientific analytical applications, and a growing interest in documentary sources on techniques and materials past and present.' Erma Hermens, 'Technical Art History: The Synergy of Art, Conservation and Science,' in Art History and Visulal Studies in Europe: Transnational Discourses and National Frameworks, ed. Matthew Rampley et al. (Leiden and Boston: Brill, 2012), 151. See also Ainsworth, 'From Connoisseurship to Technical History.'

11. See, for example, Pip Laurenson, 'Shifting Structures, Identity and Change in the Conservation and Management of Time-Based Media Works of Art.' (PhD diss., University College London, 2011) and Salvador Muñoz Viñas, Contemporayy Theory of Conservation (Oxford: Elsevier, 2005).

12. Steven W. Dykstra, 'The Artist's Intentions and the Intentional Fallacy in Fine Arts Conservation,' JAIC 35, 5 (1996): 201.

13.Cf. Miriam Clavir, Preserving What is Valued: Museum, Conservation and First Nations (Vancouver and Toronto: UBC Press, 2002) and Muñoz Viñas, Contemporary Theory of Conservation, 65-66.

14. See Caroline Villers, 'Post Minimal Intervention,' The Conservator 28 (2004), 3-10.

15. Villers, 'Post Minimal Intervention.'

16. I refer to the concept rather than the contemporary literal sense of the word artist, instead Vasari's subject is referred to as an artefice (artificer).

17. This development goes hand in hand with the new models of decentralized and inclusive museology.

18. This echoes Actor Network Theory (ANT), the Science and Technology Studies (STS) approach developed in the 1980s, which assigns technological objects an agency equivalent to humans.

19. To mention only the invaluable intellectual project authored by Miriam Clavir. Clavir, Preserving What is Valued.

20. Paul, Philippot. 'Restoration From the Perspective of the Humanities,' in Historical and Philosophical Issues in the Conservation of Cultural Heritage, edited by Nicholas Stanley Price et al. (Los Angeles: J. Paul Getty Trust, 1996), 216. 
21. Philippot, 'Restoration from the Perspective of the Humanities,' 217. Boito's curious sounding theory advocated the preservation of the history of monument and its modification, keeping all contemporary restorations and additions visible and distinguishable from historical elements; he emphasised conservation over restoration and refuted stylistic restorations.

22. Theory of Restoration outlined the theoretical and practical framework for restoration and included guidelines on what is ethically acceptable and unacceptable in restoration. Cesare Brandi, Theory of Restoration, trans. Cynthia Rockwell (Nardini Editore: Florence, 2005), 62.

\section{Brandi, Theory of Restoration, 48.}

24. Helen Glanville, Introduction to The History of the Restoration and Conservation of Works of Art by Alessandro Conti, translated by Helen Glanville (London: Elsevier, 2007), xx.

25. For an overview of Brandian axioms, see Sebastiano Barassi, 'Dreaming of a Universal Approach: Brandi's Theory of Restoration and the Conservation of Contemporary Art' (paper presented at the seminar Conservation, Principles, Dilemmas and Uncomfortable Truths, Royal Academy of Arts, September 24, 2009). http://www.icom-cc.org/54/document/dreaming-of-a-universalapproach-brandis-theory-of-restoration-and-the-conservation-of-contemporary-art/ ?id=777\#. (accessed 16 April 2017).

\section{Brandi, Theory of Restoration, 47.}

27. Reflected in a series of articles published in the Burlington Magazine by multiple authors, the National Portrait Gallery controversy revolved around the cleaning of paintings and issues of intentionality. It is considered an example of the rupture between the scientific/technological approach and attitudes emphasizing the validity of historic and artistic argument (including aging and patina and involving comparative, observational methods). For example, see Cesare Brandi, 'The Cleaning of Pictures in Relation to Patina, Varnish and Glazes,' The Burlington Magazine 91, no. 556 (1949):183-189. Also see Steven W. Dykstra, 'The Artist's Intentions,' 20.

28. Ennst Gombrich, 'Letters on Restoration: Sir Ernst Gombrich to Sarah Walden 1982-2001,' in The Ravished Image: An Introduction to the Art of Picture Restoration and its Risks, edited by Sarah Walden (London: Gibson Square Books, 2004), 171. See also Ernst Gombrich, 'Dark Varnishes: Variation on a Theme from Pliny,', in The Ravished Image: An Introduction to the Art of Picture Restoration and its Risks, ed. Sarah Walden (London: Gibson Square Books, 2004), 135-148.

29. Thordis Arrhenius, The Fragile Monument: On Conservation and Modernity (London: Artifice Books and Black Dog Publishing, 2012), 48.

30. The distinction between traditional and contemporary conservation theory was clearly articulated by Salvador Muñoz Viñas, whereby he speaks of 'classical' rather than 'traditional' conservation, see Muñoz Viñas, Contemporary Theory of Conservation. In the field of conservation of time-based media installations, the critique of the traditional 'conservation object' was undertaken by Pip Laurenson in her 2006 article 'Authenticity, Change and Loss in the Conservation of Time-Based Media', Tate Papers, 6, (2006) http://www.tate.org.uk/research/publications/tate-papers/authenticity-change-andloss-conservation-time-based-media (accessed 03 April 2017).

31. If we follow Hassard, tangible heritage became separated from intangible heritage only recently causing a sense of discontinuity with the past, which he associates with the practice of restoration and its patrimony of expertise. Institutionalized heritage is inseparable from the ideological site of the museum where objects are housed, mediated and conserved and where, by these very means, meaning is conferred upon them. Frank Hassard, 'Heritage, Hermeneutics and Hegemony: A Study of Ideological Division in the Field of Conservation-Restoration' (Ph.D 
diss., Brunel University, November 2006).

32. The discussion of an object as a sum of its transitions might be already seen in the work of David Lowenthal who recognizes the historical palimpsests of built heritage and values its endurance through a sequence of changes rather than an original or originating state. See, for example, David Lowenthal. 'Changing Criteria of Authenticity,' in Nara Conference on Authenticity in Relation to the World Heritage Convention, ed. Knut Einar Larsen (Paris: UNESCO, ICCROM, and ICOMOS, 1995), 121-35.

33. Naum Gabo's reconstructed modernist sculptures in the Tate collection or a one third reconstruction of the Palmyra Arch destroyed in Syria by ISIS, and later exhibited in Trafalgar Square in April 2016 (amongst other places) might be further examples. For discussion of Harvard Art Museum's augmented reality project for Mark Rothko's Harvard Murals see Hanna Hölling 'Lost to Museums? Changing Media, Their World, and Performance,' in special issue 'Lost Museums', Museum History Journal 10, 1 (2017): 97-111.

34. Martin Heidegger, 'The Question Concerning Technology.' In The Questions Concerning Technology and Other Essays, translated by W. Lovit (New York: Harper and Row, 1977), 3-35.

35. Heidegger, 'The Question Concerning Technology.' 
Holling Cpation

Fig 1: Jeff Wall, Restoration, 1993. Transparency in lightbox, 119.0 x 489.6 $\mathrm{cm}$. Courtesy of the artist

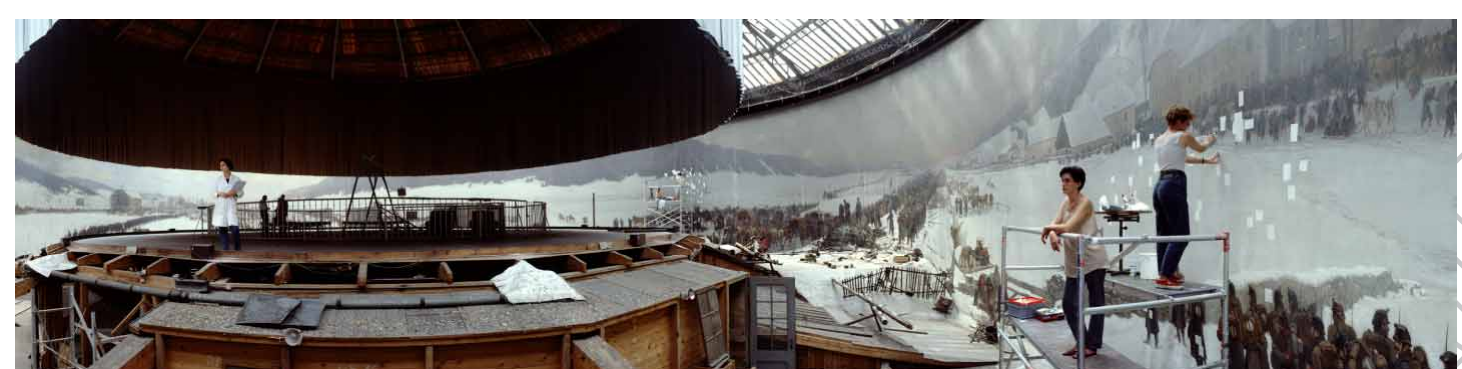

